\title{
SÍNTESE DOS CENÁRIOS PALEOBIOCLIMÁTICOS DO QUATERNÁRIO TARDIO EM MINAS GERAIS/SUDESTE DO BRASIL
}

\section{Synthesis of the Late-Quaternary palaeobioclimatic scenarios in Minas Gerais State/Southeastern Brazil}

Luiz Fernando de Paula Barros Bacharel em Geografia e mestrando em Geografia e Análise Ambiental pela Universidade Federal de Minas

Gerais (UFMG). Bolsista CNPq. Belo Horizonte/MG - Brasil luizfpbarros@yahoo.com.br

Chrystiann Lavarini Graduando em Geografia pelo Instituto de Geociências (IGC) da Universidade Federal de Minas Gerais (UFMG)

Belo Horizonte/MG - Brasil lavarini.c@gmail.com

Laura Souza Lima Universidade Federal de Minas Gerais Belo Horizonte/MG - Brasil laurasouzalima@yahoo.com.br

Antônio Pereira Magalhães Júnior Professor Adjunto do Departamento de Geografia do Instituto de Geociências (IGC) da Universidade Federal de Minas Gerais (UFMG)

Belo Horizonte/MG - Brasil magalhaesufmg@yahoo.com.br

Artigo recebido para publicação em 11/07/2011 e aceito para publicação em 25/10/2011.

RESUMO: O presente trabalho apresenta uma tentativa de síntese das contribuições teóricas sobre os cenários paleobioclimáticos naturais do Quaternário Tardio no Estado de Minas Gerais, sudeste do Brasil, buscando sua relação com eventos climáticos de larga escala. Para tanto, foi feita uma extensa revisão da literatura em periódicos e fontes diversas. Buscaram-se trabalhos com diferentes metodologias, mas que apresentam datações absolutas e cujos resultados possuem implicações paleobioclimáticas. Em levantamentos desse tipo dificilmente podem ser estabelecidos limites temporais precisos para os periodos identificados. No entanto, algumas tendências foram observadas a partir do conjunto de dados disponíveis. Nesse sentido, foram propostos oito cenários paleobioclimáticos para os últimos 50 $\mathrm{ka}$, sendo que nos últimos $10 \mathrm{ka}$, geralmente, se verifica um maior número de cenários. Essa proposta, entretanto, ainda está em aberto, pois os dados disponiveis estão concentrados em algumas regiões do Estado, ocorrendo vazios de informações.

Palavras-chave: Mudanças ambientais. Registros quaternários continentais. Geocronologia. Estado de Minas Gerais. 
ABSTRACT: In this paper, it was attempted to synthesize the natural palaeobioclimatic scenarios of the Late-Quaternary in Minas Gerais State, Southeastern Brazil, seeking for their relationship to large-scale climatic events. It was made an extensive literature review. It was looked for papers based on different methods, but with absolute datings and palaeobioclimatic implications. This kind of survey can not set precise time limits. However, some trends could be observed from the available datasets. It was proposed eight palaeobioclimatic scenarios for the last 50,000 years. The greater number of scenarios is usually found in the last 10,000 years. However, this proposal is still open due to concentration of the available data in just some regions, occurring information gaps.

Keywords: Environmental changes. Quaternary continental records. Geochronology. Minas Gerais State.

\section{INTRODUÇÃO}

As mudanças climáticas durante o Quaternário são de interesse transversal na geografia e demais ciências naturais, uma vez que podem ter desencadeado desde migrações de grupos humanos durante o Holoceno (ARAUJO et al., 2005) até reestruturações de paisagens em larga escala (BEHLING, 2002; LEDRU et al., 1998a; SALGADO-LABOURIAU et al., 1998). As instabilidades no clima e na vegetação da transição Pleistoceno-Holoceno na América do Sul também teriam reduzido drasticamente a quantidade de indivíduos de espécies animais, fomentando o desequilíbrio populacional e, conseqüentemente, uma extinção tão violenta quanto à dos dinossauros, sem qualquer existência de meteorito (CARTELLE, 1994). Além disso, precipitação e temperatura controlam uma série de reações e processos químicos e físicos e o tipo de vegetação, determinando o comportamento de sistemas geomorfogenéticos de diferentes escalas (MIALL, 2006; SCHUMM, 2005).

As mudanças climáticas quaternárias são causadas principalmente por condicionantes orbitais e por anomalias no comportamento dos oceanos. Segundo Ferreira (2002), a despeito de teorias clássicas, que preconizavam quatro ou cinco glaciações durante o Quaternário, a estratigrafia isotópica dos fundos oceânicos mostra que os ciclos glaciários são da ordem de duas dezenas nos últimos dois milhões de anos e a alternância entre fases úmidas e secas parece ser ainda maior.

Em geral, as investigações paleobioclimáticas continentais são baseadas em registros polínicos e geoquímicos/geofísicos, macrofósseis, microfósseis, anéis de árvores, isótopos estáveis, susceptibilidade magnética, etc. (RODRIGUES-FILHO et al., 2002). No entanto, a maioria das reconstruções paleoambientais do Pleistoceno Superior e do Holoceno são baseadas em registros polínicos (PESSENDA et al., 2004; THOMAS et al., 2001).

Atualmente existem mais de 40 métodos aplicáveis à datação de materiais associados a eventos do Quaternário (SALLUN et al., 2007). Obter a cronologia destes eventos é uma importante ferramenta para a compreensão das respostas dos sistemas naturais às alterações em fatores como clima, tectônica e condicionantes antrópicos, além de permitir a correlação de depósitos e eventos, a fim de se construir sínteses e modelos regionais. Na região neotropical da America do Sul, entretanto, a despeito de sua importância para a dinâmica do clima do passado e do presente (JACOB et al., 2007), a magnitude e o modo das mudanças paleoambientais ainda são bastante desconhecidos devido à falta de registros paleoecológicos, sobretudo durante o Último Máximo Glacial (LEDRU et al., 1998a; URREGO et al., 2005).

Para uma melhor compreensão das atuais transformações ambientais e possíveis previsões de respostas dos ecossistemas a futuras mudanças climáticas é forçoso investigar a natureza e a magnitude das mudanças passadas no ambiente e conhecer as interações entre biosfera, atmosfera e oceano (ANHUF et al., 2006; KRAMER; STEVAUX, 2001; PESSENDA et al., 1996; RODRIGUES-FILHO et al., 2002). Esse tipo de conhecimento é essencial inclusive para conservação e criação de bases para a regeneração de biomas, como a Mata Atlântica (LEDRU et al., 2009), reduzida a apenas $7 \%$ de seu tamanho original devido às atividades antrópicas (SOS MATAATLÂNTICA, 2011). 
De acordo com Lino (2010), esse é um tipo de análise que não pode ser "politizada", pois as atuais discussões sobre o chamado "aquecimento global" nada teriam a ver com evidências científicas, mas com uma agenda determinada por interesses políticos, econômicos e acadêmicos restritos. No entanto, o conhecimento da influência humana sobre a atmosfera e o clima da Terra desde o início do século XX tem levado a um esforço global para analisar a dimensão, as causas e as conseqüências das mudanças climáticas ditas antropogênicas (HOUGHTON et al., 2001). Estas são entendidas como mudanças climáticas associadas às atividades humanas, como o aumento da emissão de gases de efeito estufa com queimadas e desmatamentos, a formação de ilhas urbanas de calor, etc. (ABREU; ASSIS, 1998; NOBRE et al., 2007; VIANELLO, 1976).

O presente trabalho apresenta uma tentativa de síntese das contribuições teóricas sobre os cenários paleobioclimáticos não antrópicos do Quaternário Tardio em Minas Gerais, buscando sua relação com eventos climáticos de larga escala. Com isso, pretende-se elaborar um guia para que futuras pesquisas possam estabelecer melhores correlações dos eventos por elas identificados com as mudanças e flutuações climáticas do final do Pleistoceno Superior e do Holoceno no Estado. Acredita-se que a dispersão das informações e a falta de revisões completas e mais regionalizadas vêm limitando esse tipo de esforço.

A maioria das revisões já existentes é baseada apenas em dados palinológicos e possuem, muitas vezes, focos específicos. Por exemplo, Salgado-Labouriau (1997) e Salgado-Labouriau et al. (1998) analisam dados até então disponíveis para as áreas de Cerrado do Brasil Central. Ledru et al. (1998a) limitam sua análise da dinâmica vegetacional do sul e sudeste aos últimos $10 \mathrm{ka}$. Por sua vez, Behling (2002) traz uma síntese focada na fachada atlântica do sul e sudeste do Brasil a fim de analisar a dinâmica da vegetação de campos (grasslands).

\section{CENÁRIOS BIOCLIMÁTICOS ATUAIS EM MINAS GERAIS}

No Estado de Minas Gerais coexistem três grandes unidades bióticas de escala regional (Cerrado, Mata Atlântica e Caatinga), além de Refúgios Vegetacionais (Comunidades Relíquias) mais restritos, denominados montanos e alto-montanos (IBGE, 2004a). Esta diversidade está ligada às variadas condições climáticas, edáficas e hidrológicas verificadas no Estado, o qual possui grande extensão tanto latitudinal como longitudinal (Figura 1).

Figura 1: Precipitação, temperatura e principais formações vegetais em Minas gerais $(\mathrm{BH}=\mathrm{Belo}$ Horizonte, capital do Estado).

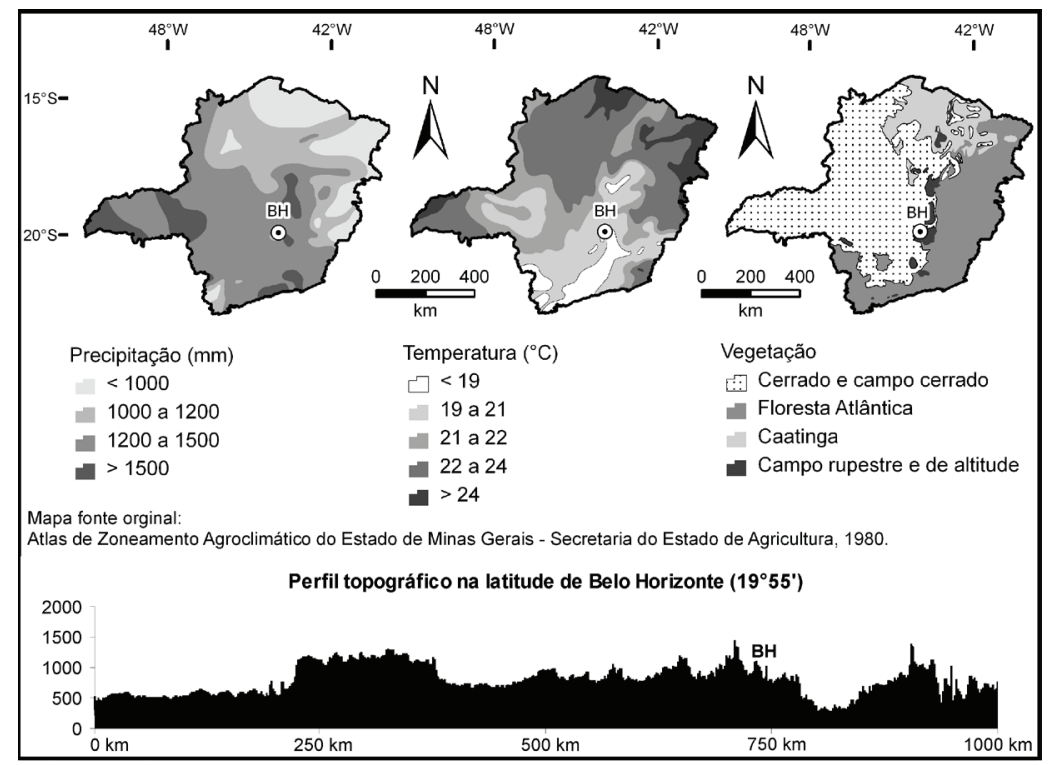


O Bioma Cerrado domina as porções de centro, centro-oeste e noroeste de Minas Gerais, compreendendo $57 \%$ do território mineiro. O cerrado é provavelmente a mais antiga formação vegetal no Estado, podendo remontar ao período Cretáceo, antes da separação do supercontinente Gondwana (RATTER et al., 1997). Nesse grande compartimento biótico predominam diversas formações florestais e campestres, destacando-se: (i) a Savana Arborizada (campo cerrado e cerrado), (ii) a Savana Gramínio-Lenhosa (campo-limpo-de-cerrado), (iii) Savana Parque (campo-sujo-de-cerrado) e, ao longo de alguns rios, (iv) Galerias Florestais, além de manchas esporádicas de (v) Florestas Secas Semidecíduas (matas secas) sobre afloramentos calcários, geralmente circundados por (vi) Cerradão (IBGE, 2004b).

O Cerrado mineiro, segundo a síntese de classificação climática de Köppen, possui três climas: Cwa nas porções oeste, centro e norte; Aw nos segmentos noroeste, nordeste e extremo oeste; e Cwb em um pequeno trecho no centro-leste do Estado. A precipitação média é de $1.100-1500 \mathrm{~mm} / \mathrm{ano}$, com 81 a 100 dias chuvosos (ALMEIDA, 1995). A temperatura média anual nesse bioma em Minas Gerais varia de $20^{\circ} \mathrm{C}$ (porção central) a $24^{\circ} \mathrm{C}$ (segmentos oeste e norte), com sensível diminuição de norte para sul (BRASIL, 1992; NIMER, 1989).

A Mata Atlântica corresponde ao segundo bioma de maior expressão territorial em Minas Gerais, com $41 \%$ de área ocupada, estando circunscrita, primordialmente, à faixa leste e centro-sul do Estado, com pequenas manchas ao longo dos vales dos rios Paranaíba e Grande, no extremo-oeste. Nesse bioma convivem formações florestais típicas dessa unidade fitoecológica, bem como áreas de contato (tensão ecológica), principalmente nas proximidades da Caatinga e do Cerrado. As tipologias observadas no Bioma Mata Atlântica são: (i) Floresta Ombrófila Densa (Floresta Tropical Pluvial); (ii) Floresta Ombrófila Mista (Floresta de Araucária) e (iii) Floresta Estacional Semidecidual (Floresta Tropical Subcaducifólia). Nas faixas de tensão ecológica ocorrem contatos entre: (i) Savana Estépica e Floresta Estacional, (ii) Floresta Ombrófila Densa e Mista e, por fim, entre (iii) Floresta Estacional e Floresta Ombrófila Mista (IBGE, 2004b). Destaca-se que, segundo Silva et al. (2004), a ocorrência de zonas de tensão ecológica revela condicionantes de mudanças paleoclimáticas (DESJARDINS et al., 1996), já que a diferenciação dos ecossistemas nem sempre pode ser atribuída a fatores edáficos, geomorfológicos e hidrológicos (CARNEIRO FILHO, 1993).

Segundo a classificação climática de Köppen, este bioma apresenta quatro climas principais: Aw na faixa leste-nordeste; na porção centro-leste domina o Cwa, porém ocorre uma área classificada como $\mathrm{Cwb}$ em seu centro; e Cfb no sul. As temperaturas médias anuais estão entre 18 e $26^{\circ} \mathrm{C}$, variando latitudinalmente e altimetricamente, sendo o relevo o maior condicionante da variabilidade climática (BRASIL, 1992; IBGE, 2004b; NIMER, 1989). A precipitação média varia de $850 \mathrm{~mm} /$ ano (no quadrante nordeste) a $1.650 \mathrm{~mm} /$ ano (na região centro-sul), sem período seco sistemático (BRASIL, 1992; IBGE, 2004b).

Tanto o Cerrado como a Mata Atlântica possuem formações campestres, os chamados campos rupestres e campos de altitude, que se caracterizam por mosaicos de tipologias vegetais mais corretamente denominados de Complexos Rupestres e de Altitude. Estes complexos estão representados, principalmente, nas elevações acima de $900 \mathrm{~m}$ na Serra do Espinhaço e acima de 1500-2000 m nas serras do Mar e da Mantiqueira, onde se distinguem das formações savânicas e florestais adjacentes (BENITES et al., 2003; FERRI 1980).

O Bioma Caatinga, por sua vez, ocupa apenas $2 \%$ da área do Estado, estando restrito à porção extremo norte, dentro da bacia hidrográfica do Rio São Francisco. A vegetação preponderante é de tensão ecológica, com contato entre a Savana Estépica (caatinga do sertão árido) e a Floresta Estacional (IBGE, 2004b).

$\mathrm{Na}$ classificação de Köppen, esse trecho apresenta um clima Aw, com bordas próximas à classificação em Cwa. A temperatura média anual é a mais elevada do Estado, variando entre 26 e $28^{\circ} \mathrm{C}$, enquanto a precipitação média anual varia de 650 a $1050 \mathrm{~mm} /$ ano (BRASIL, 1992). O clima da Caatinga na porção mineira apresenta valores de umidade e precipitação/evaporação mais uniformes em comparação aos trechos do nordeste brasileiro, apresentando chuvas acumuladas entre novembro e fevereiro-março, seguidas por um período seco de aproximadamente seis meses (RIZZINI, 1979). 


\section{METODOLOGIA E DADOS UTILIZADOS}

Foi feita uma extensa revisão da literatura em periódicos e fontes diversas em busca de trabalhos que apresentam datações absolutas e cujos resultados possuem implicações paleobioclimáticas. Na Tabela
1 é apresentado um sumário dos trabalhos utilizados para a proposta e discussão dos cenários paleobioclimáticos. Já na Figura 2 é representada a localização dos diferentes sítios analisados nos domínios atuais de vegetação em Minas Gerais.

Tabela 1: Sumário dos sítios (de Oeste para Leste) e trabalhos analisados.

\begin{tabular}{|c|c|c|c|c|c|c|}
\hline ID & Nome & Localização & $\begin{array}{l}\text { Elevação } \\
\text { (m) }\end{array}$ & $\begin{array}{l}\text { Datações } \\
\text { (milhares de } \\
\text { anos) }\end{array}$ & Métodos & Referência \\
\hline 1 & Uberaba & $\begin{array}{l}\text { 19²3'01"S, } \\
48^{\circ} 54^{\prime} 06^{\prime \prime} \mathrm{W}\end{array}$ & 650 & $\begin{array}{c}27,5 \pm 0,9 \\
{ }^{14} C^{* * *}\end{array}$ & Análise de fitólitos & $\begin{array}{l}\text { Borba-Roschel } \\
\text { et al. }(2006)\end{array}$ \\
\hline \multirow[b]{3}{*}{2} & \multirow[b]{3}{*}{ Salitre* } & \multirow[b]{3}{*}{$\begin{array}{l}19^{\circ} \mathrm{S} \\
46^{\circ} 46^{\prime} \mathrm{W}\end{array}$} & \multirow[b]{3}{*}{1050} & $3-30{ }^{14} \mathrm{C}$ & Palinológicos & Ledru (1993) \\
\hline & & & & $0-50{ }^{14} \mathrm{C}$ & Palinológicos & $\begin{array}{l}\text { Ledru et al. } \\
\text { (1996) }\end{array}$ \\
\hline & & & & $0.2-9{ }^{14} \mathrm{C}$ & $\begin{array}{c}\text { Análise de isótopos } \\
\text { de carbono da } \\
\text { matéria orgânica do } \\
\text { solo }\end{array}$ & $\begin{array}{l}\text { Pessenda et al. } \\
\text { (2004) e } \\
\text { Pessenda et al. } \\
\text { (1996) }\end{array}$ \\
\hline 3 & $\begin{array}{l}\text { Serra } \\
\text { Negra }\end{array}$ & $\begin{array}{c}19^{\circ} \mathrm{S} \\
46^{\circ} 45^{\prime} \mathrm{W}\end{array}$ & 1170 & $0-50{ }^{14} \mathrm{C}$ & Palinológicos & Oliveira (1992) \\
\hline 4 & $\begin{array}{l}\text { Bacia do } \\
\text { Ribeirão } \\
\text { dos } \\
\text { Poncianos }\end{array}$ & $\begin{array}{l}22^{\circ} 45^{\prime} 17^{\prime \prime} \mathrm{S} \\
46^{\circ} 08^{\prime} 41^{\prime \prime} \mathrm{W}\end{array}$ & $\begin{array}{c}\sim 1000- \\
1300\end{array}$ & $26-35 \mathrm{LOE}^{* *}$ & Estratigráficos & $\begin{array}{c}\text { Missura e } \\
\text { Corrêa (2007) }\end{array}$ \\
\hline 5 & $\begin{array}{l}\text { Serra de } \\
\text { São José }\end{array}$ & $\begin{array}{l}21^{\circ} 03^{\prime} 57^{\prime \prime} \mathrm{S}, \\
44^{\circ} 06^{\prime} 53^{\prime \prime} \mathrm{W}\end{array}$ & 1350 & $0-32{ }^{14} \mathrm{C}$ & $\begin{array}{l}\text { Estratigráficos e } \\
\text { (geo)químicos }\end{array}$ & $\begin{array}{l}\text { Silva et al. } \\
\quad(2004)\end{array}$ \\
\hline 6 & $\begin{array}{l}\text { Lagoa dos } \\
\text { Olhos }\end{array}$ & $\begin{array}{l}19^{\circ} 38^{\prime} \mathrm{S}, \\
43^{\circ} 54^{\prime} \mathrm{W}\end{array}$ & 730 & $0-20{ }^{14} \mathrm{C}$ & Palinológicos & Oliveira (1992) \\
\hline 7 & $\begin{array}{l}\text { Lagoa } \\
\text { Santa }\end{array}$ & $\begin{array}{l}19^{\circ} 38^{\prime} \mathrm{S}, \\
43^{\circ} 54^{\prime} \mathrm{W}\end{array}$ & 740 & $0-10{ }^{14} \mathrm{C}$ & Palinológicos & $\begin{array}{c}\text { Parizzi et al. } \\
\text { (1998) }\end{array}$ \\
\hline 8 & $\begin{array}{l}\text { Cerca } \\
\text { Grande }\end{array}$ & $\begin{array}{l}19^{\circ} 31^{\prime} 51 " \mathrm{~S} \\
44^{\circ} 01^{\prime} 23^{\prime \prime} \mathrm{W}\end{array}$ & 670 & $3-10{ }^{14} \mathrm{C}$ & \multirow{2}{*}{$\begin{array}{c}\text { Datação de camadas } \\
\text { orgânicas }\end{array}$} & \multirow{2}{*}{$\begin{array}{l}\text { Araújo et al. } \\
\qquad(2005)\end{array}$} \\
\hline 9 & Sumidouro & $\begin{array}{l}19^{\circ} 32^{\prime} 29^{\prime \prime} \mathrm{S}, \\
43^{\circ} 56^{\prime} 29^{\prime \prime} \mathrm{W}\end{array}$ & 650 & $1,5-3{ }^{14} \mathrm{C}$ & & \\
\hline 10 & $\begin{array}{l}\text { Bacia do } \\
\text { Rio } \\
\text { Maracujá }\end{array}$ & $\begin{array}{l}20^{\circ} 21^{\prime} 09^{\prime \prime} \mathrm{S}, \\
43^{\circ} 40^{\prime \prime} 15^{\prime \prime} \mathrm{W}\end{array}$ & $\sim 1100$ & $5-32{ }^{14} C^{* * *}$ & $\begin{array}{l}\text { Palinológicos e } \\
\text { estratigráficos }\end{array}$ & $\begin{array}{l}\text { Gomes et al. } \\
\text { (2009) }\end{array}$ \\
\hline 11 & Catas Altas & $\begin{array}{l}20^{\circ} 05^{\prime} \mathrm{S} \\
43^{\circ} 22^{\prime} \mathrm{W}\end{array}$ & 755 & $18-48{ }^{14} \mathrm{C}$ & Palinológicos & $\begin{array}{c}\text { Behling e } \\
\text { Lichte (1997) }\end{array}$ \\
\hline 12 & $\begin{array}{l}\text { Lago Dom } \\
\text { Helvécio }\end{array}$ & $\begin{array}{l}19^{\circ} 40^{\prime} 45^{\prime \prime} \mathrm{S} \\
42^{\circ} 35^{\prime} 40^{\prime \prime} \mathrm{W}\end{array}$ & 280 & $1,5-8,5{ }^{14} \mathrm{C}$ & $\begin{array}{l}\text { Sedimentológicos, } \\
\text { químicos, } \\
\text { microscópicos e } \\
\text { análise da } \\
\text { acumulação total de } \\
\text { carbono }\end{array}$ & $\begin{array}{l}\text { Turcq et al. } \\
\quad(2002)\end{array}$ \\
\hline 13 & $\begin{array}{l}\text { Lago } \\
\text { Silvana }\end{array}$ & $\begin{array}{l}19^{\circ} 31^{\prime} \mathrm{S} \\
42^{\circ} 25^{\prime} \mathrm{W}\end{array}$ & 230 & $0-10{ }^{14} \mathrm{C}$ & Palinológicos & $\begin{array}{l}\text { Rodrigues- } \\
\text { Filho et al. } \\
\quad(2002)\end{array}$ \\
\hline 14 & $\begin{array}{l}\text { Lago do } \\
\text { Pires }\end{array}$ & $\begin{array}{l}17^{\circ} 57^{\prime} \mathrm{S} \\
42^{\circ} 13^{\prime} \mathrm{W}\end{array}$ & 390 & $0-10{ }^{14} \mathrm{C}$ & Palinológicos & Behling (1995) \\
\hline 15 & $\begin{array}{l}\text { Lagoa } \\
\text { Nova }\end{array}$ & $\begin{array}{l}17^{\circ} 58^{\prime} \mathrm{S}, \\
42^{\circ} 12^{\prime} \mathrm{W}\end{array}$ & 390 & $0-10{ }^{14} \mathrm{C}$ & Palinológicos & Behling (2003) \\
\hline 16 & $\begin{array}{l}\text { Lago } \\
\text { Aleixo }\end{array}$ & $\begin{array}{l}17^{\circ} 59^{\prime} \mathrm{S} \\
42^{\circ} 07^{\prime} \mathrm{W}\end{array}$ & 390 & $0-10{ }^{14} \mathrm{C}$ & Palinológicos & $\begin{array}{c}\text { Enters et al. } \\
(2010)\end{array}$ \\
\hline 17 & $\begin{array}{l}\text { Lago Água } \\
\text { Preta de } \\
\text { Baixo }\end{array}$ & $\begin{array}{l}18^{\circ} 25^{\prime} \mathrm{S}, \\
41^{\circ} 50^{\prime} \mathrm{W}\end{array}$ & 240 & $0-10{ }^{14} \mathrm{C}$ & $\begin{array}{l}\text { Sedimentológicos, } \\
\text { químicos, } \\
\text { microscópicos e } \\
\text { análise da } \\
\text { acumulação total de } \\
\text { carbono }\end{array}$ & $\begin{array}{l}\text { Turcq et al. } \\
\text { (2002) }\end{array}$ \\
\hline
\end{tabular}

* Um mesmo sítio, porém análises com dados complementares. ** LOE = Luminescência Opticamente Estimulada. *** Dados de estudos anteriores. 
Figura 2: Localização dos sítios estudados no quadro vegetacional atual.

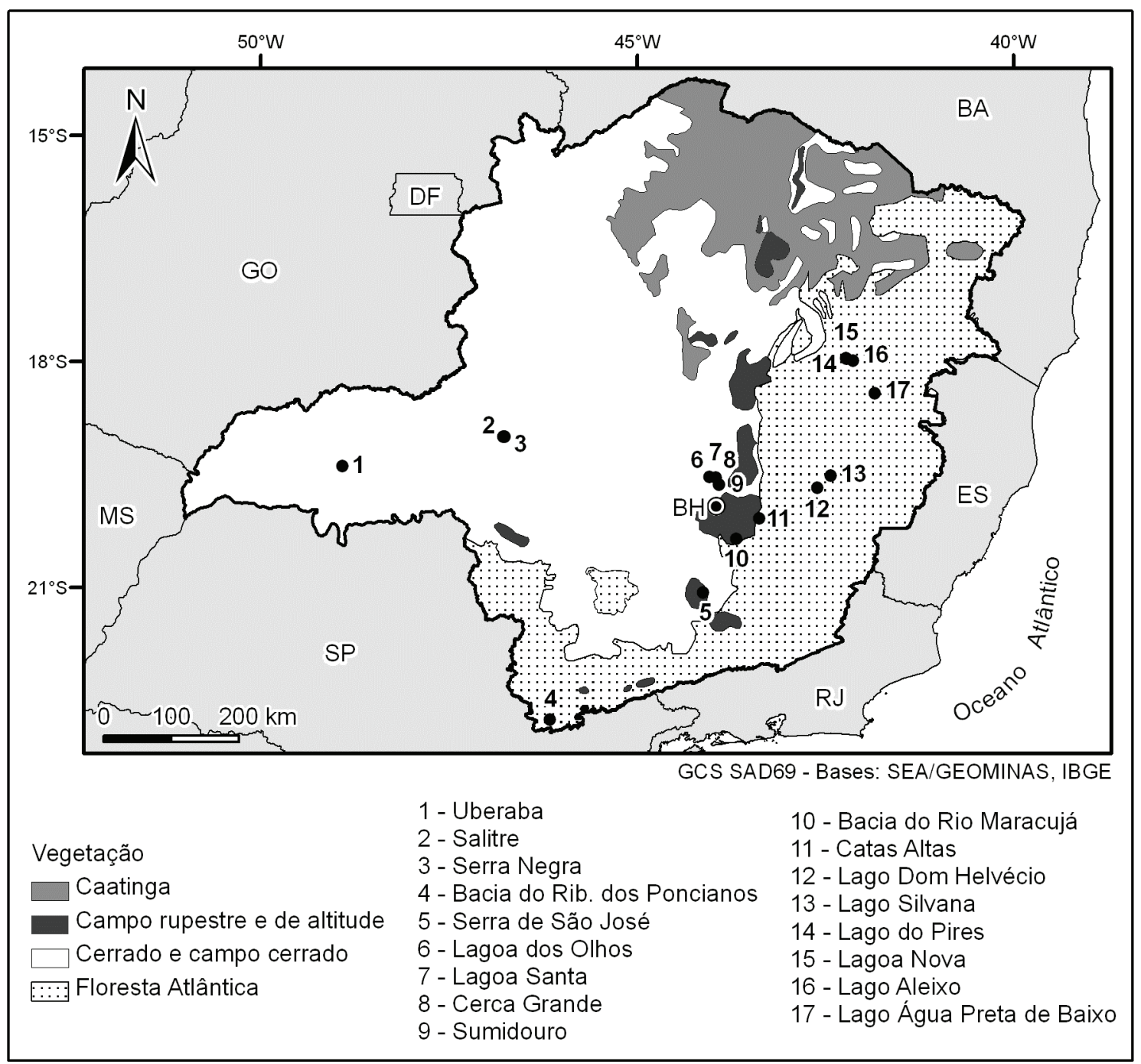

\section{RESULTADOS E DISCUSSÕES}

A correlação de eventos de natureza climática é dificultada por uma série de fatores. De acordo com Salgado-Labouriau (1997) e Thomas (2000), destacam-se: (i) além da margem de erro das datações (desvios padrão de centenas ou milhares de anos), os eventos identificados podem variar em idade de um local para outro, por exemplo, em razão da posição estratigráfica das amostras colhidas para datação, diferenças entre a idade do material da amostra e a idade de deposição, contaminação da amostra, além de erros inerentes aos métodos de datação utilizados; (ii) hiatos nos sinais dos dados; (iii) a dispersão dos dados, o que obriga a levar em conta os efeitos de gradientes climáticos regionais e diferenças de regime; (iv) as especificidades do local e do material amostrado; (v) a ausência de calibração em algumas datações; (v) a interpolação ou extrapolação pelos autores da idade de um evento específico, assumindo uma taxa constante de sedimentação; (vi) a adoção de diferentes métodos na análise polínica.

Nesse sentido, dificilmente fases climáticas com limites temporais precisos podem ser estabelecidas. No entanto, a partir do conjunto de dados disponíveis para Minas Gerais algumas tendências foram observadas, as quais baseiam a proposição de oito cenários paleobioclimáticos, que serão apresentados a seguir do mais antigo para o mais recente. 


\section{Cenário 1}

Os dados palinológicos disponíveis para os últimos $50 \mathrm{ka} \mathrm{AP} \mathrm{(aproximadamente} \mathrm{o} \mathrm{limite} \mathrm{da} \mathrm{da-}$ tação radiocarbônica) indicam um clima mais seco e mais frio que o atual a esta época. Esse momento seria caracterizado pela dominância de campos (especialmente a Família Poaceae), porém com a ocorrência de alguma mata galeria com a presença de Araucaria (BEHLING ; LICHTE, 1997; LEDRU et al., 1996). Com base na atual distribuição das populações de campos e Araucaria, Behling e Lichte (1997) propõem para esse período temperaturas entre 5 e $7^{\circ} \mathrm{C}$ mais baixas que as atuais na região de Catas Altas, porção central do Estado.

\section{Cenário 2}

O período seguinte seria mais úmido, segundo Ledru et al. (1996), de acordo com a ocorrência de florestas de planície entre 40 e $27 \mathrm{ka}$ AP. No registro de Serra Negra, Oliveira (1992) identifica entre 50 e $32 \mathrm{ka} \mathrm{AP} \mathrm{um} \mathrm{mosaico} \mathrm{florestal} \mathrm{com} \mathrm{taxons} \mathrm{indicadores}$ de clima frio e de clima quente. Segundo Ledru et al. (1996), apesar de serem sítios muito próximos (distantes menos de $2 \mathrm{~km}$ ), as mudanças no conjunto dos pólens não são as mesmas em Salitre e Serra Negra, porém as interpretações paleoclimáticas são compatíveis se levados em conta fatores como topografia, altitude e sedimentologia.

Para Salgado-Labouriau et al. (1998) o período entre 36 e 22-18 ka AP era possivelmente de um clima pouco mais úmido ou próximo ao encontrado hoje na região sudeste, com uma estação seca menor e temperatura provavelmente mais elevada, pois há registro da ocorrência de buritizeiros e outras árvores tropicais. A partir de um levantamento dos ritmos de sedimentação de uma lagoa no topo da Serra São José (município de Prados), Silva et al. (2004) concordam com uma maior umidade neste período, que se estenderia até $21 \mathrm{ka} \mathrm{AP,} \mathrm{seu} \mathrm{ápice.} \mathrm{Já} \mathrm{com} \mathrm{base} \mathrm{na} \mathrm{análise} \mathrm{de}$ eventos de coluvionamento na Mantiqueira Ocidental com datação via Luminescência Opticamente Estimulada (LOE), Missura e Corrêa (2007) consideram que entre 35 e $26 \mathrm{ka}$ AP o clima teria oscilado duas vezes entre úmido e seco, favorecendo eventos dessa natureza. Em $27.200 \pm 3.500$ o clima já estaria num segundo período seco (MISSURA; CORRÊA, 2007).

Entretanto, Behling; Lichte (1997) não mostram uma divisão no período entre 48 e $27 \mathrm{ka}$ AP, indicando a manutenção das condições mais frias e secas que as atuais, indicadas anteriomente. Em acordo com esses autores, a partir da análise de um testemunho sedimentar poucos quilômetros distante, Gomes et al. (2009) apresentam um quadro com domínio da flora de Cyperaceae e Poaceae, ausência de elementos arbóreos e baixa diversidade de esporos de pteridófitos por volta de $32 \mathrm{ka} \mathrm{AP}$. Esse quadro indicaria prováveis condições climáticas mais secas que a atual, pois a ausência destes elementos sugere que as áreas alagadiças eram de pequenas dimensões. Essa diferença entre o quadro proposto por Behling e Lichte (1997) e Gomes et al. (2009) e o apresentado acima pode revelar mecanismos específicos de aporte de umidade para as porções oeste e sul do Estado entre 40 e $27 \mathrm{ka} \mathrm{AP.}$

Tanto em Salitre como em Serra Negra os dados sugerem um hiato nos registros sedimentares durante o Último Máximo Glacial (UMG), sendo o intervalo maior em Serra Negra - 32 a 14,3 ka AP (LEDRU, 1993; LEDRU et al., 1996, OLIVEIRA, 1992).

\section{Cenário 3}

Os únicos registros polínicos entre 27 e 19 ka AP disponíveis no Estado são os apresentados por Behling e Lichte (1997). Segundo estes autores este seria um período mais seco que o anterior e muito frio, o que teria levado a uma retração de espécies arbóreas, como as do gênero Araucaria, permanecendo o domínio de campos (grasslands). Behling et al. (2002) consideraram a partir de um core marinho na foz do Rio Doce que este período se deu entre 31 e 13 ka AP, também com características de baixas temperaturas e pouca umidade.

Borba-Roschel et al. (2006) analisaram fitólitos em um registro de aproximadamente $1,3 \mathrm{~m}$ em Uberaba, porém apresentam apenas a idade da base $(27.500 \pm 900 \mathrm{ka})$, obtida em estudo anterior. Segundo aqueles autores, as famílias Cyperaceae e Poaceae dominam a vegetação atual, registros da Família 
Poaceae dominam as partes inferiores do perfil, já a Família Cyperaceae é mais comum nas partes superiores. Esse padrão pode ser atribuído a um aumento da dissolução seletiva dos fitólitos do tipo Cyperaceae com a profundidade, e/ou a uma diminuição de estresse hídrico sofrido pelas gramíneas, associado a mudanças hidrológicas locais ou regionais, levando a uma diminuição na silicificação de células buliformes (BORBA-ROSCHEL et al. 2006).

\section{Cenário 4}

Segundo Ledru (1993) e Ledru et al. (1996), entre 16 e 11 ka AP teria ocorrido um aumento gradual de umidade e as temperaturas seriam mais baixas. Uma rápida sucessão de diferentes tipos florestais nos últimos $17 \mathrm{ka}$ é interpretada por estes autores como reflexo de rápidas mudanças climáticas. Oliveira (1992) também identifica um período úmido e fresco ocorrido entre 19,5 e 13,7 ka AP em Lagoa dos Olhos, o qual seria compatível com um mosaico de floresta de dossel mais aberto.

\section{Cenário 5}

A maioria dos dados disponíveis indica que a passagem do Pleistoceno para o Holoceno em Minas Gerais foi marcada por um período climático mais seco que o atual, o que é relacionado por Ledru (1993) ao "Younger Dryas". Ainda segundo a autora, neste período desaparecem as araucárias e declina a participação de todos os gêneros de vegetação arbórea no registro de Salitre, predominando vegetação herbácea. Segundo Behling et al. (2002), proporções elevadas de pólen de espécies herbáceas nos registros referentes ao período anterior a $10 \mathrm{ka}$ indicam uma presença significativamente maior de vegetação de campos, refletindo condições marcadamente mais frias e secas durante os períodos glaciais do que hoje. Campos também são verificados neste período na área do Lago Silvana (RODRIGUES-FILHO et al., 2002). Analisando cores distantes apenas 2-3 km, Behling $(1995,2003)$ aponta para a dominância de campos e freqüentes queimadas, provavelmente naturais. Os dados de Enters et al. (2010) também confirmam o cenário de aridificação, apontando para vegetação arbórea apenas às margens de corpos hídricos. Este padrão vegetacional seria indicativo de condições climáticas secas com baixa precipitação anual e estação seca de cerca de seis meses (BEHLING, 1995, 2003; ENTERS et al., 2010). No entanto, o fim deste período seco é bem variado, podendo ter se estendido até a aproximadamente $7 \mathrm{ka}$ AP no Lago Aleixo (ENTERS et al., 2010) e a 3 ka AP em Lagoa dos Olhos (OLIVEIRA, 1992).

\section{Cenário 6}

A maioria dos trabalhos aponta para um pequeno período mais úmido no começo do Holoceno. Em Salitre, o aumento da umidade permitiu uma nova expansão do gênero Araucaria entre 9,5 e 8,5 ka AP (LEDRU, 1993). No registro analisado por Rodrigues-Filho et al. (2002) a vegetação de campos dá lugar a uma savana tropical. Ainda segundo estes autores, entre aproximadamente 9,5 e 8 ka AP percebe-se uma intensa sedimentação e ausência de pólen, o que seria uma resposta a uma intensa erosão em razão da umidificação do clima. Behling $(1995 ; 2003)$ também aponta para uma redução da estação seca e aumento do total pluviométrico, o que teria permitido uma expansão das matas galeria. As queimadas naturais foram menos freqüentes nesse período (BEHLING, 1995, 2003).

$\mathrm{O}$ aumento nos valores de Carbono Orgânico Total (TOC) registrados nos Lago Dom Helvécio e Lago do Pires reiteram a existência de uma fase úmida entre 9,9 e 8,3 ka AP (TURCQ et al., 2002). Na região central do Estado, próximo a Lagoa Santa, Araújo et al. (2005) dataram em $9.680 \pm 230$ anos AP uma camada orgânica escura nos depósitos de um lago em uma dolina próxima ao afloramento de Cerca Grande, tendo interpretado tal camada como resultado de um período com água permanente na dolina, devido a uma maior umidade. Também na região central do Estado, Gomes et al. (2009) apontam um declínio de flora herbácea de Cyperaceae e Poaceae, com reduções em até 75\%, além do aumento dos elementos arbóreos e arbustivos e a diversidade de esporos de pteridófitos. Esse quadro seria devido a um aumento gradual na umidade até a aproximadamente $5 \mathrm{ka}$ AP. Argilas muito orgânicas (turfosas) também foram datadas por Meis (1977) em depósitos adjacentes à Lagoa do Jacaré, médio Rio Doce, tendo sido obtida a idade de $9.840 \pm 220$ anos. 


\section{Cenário 7}

Um novo evento seco e bastante sazonal teria ocorrido entre 8,5 e 5,5 ka AP em Salitre e, por volta de 4,5 ka AP, uma queda abrupta no montante de pólen de espécies arbóreas é percebido (LEDRU, 1993; LEDRU et al., 1996), além do aumento de fragmentos de carvão (PESSENDA et al., 2004), testemunhando a recorrência de queimadas naturais. Turcq et al. (2002) também registraram concentrações maiores de fragmentos de carvão entre 8,7 e 6,3 ka AP no Lago da Água Preta de Baixo. Em Lagoa Nova e Lago do Pires este período foi marcado por uma retração das matas galeria, entre 7,5 e 5,5 ka AP(BEHLING, 1995, 2003). As queimadas naturais voltam a ser mais freqüentes nesse período, porém não tanto como no início do Holoceno (BEHLING, 1995, 2003). Em Lagoa Santa, até 5,4 ka AP não há registro polínico, em razão da falta de umidade (PARIZZI et al., 1998).

\section{Cenário 8}

Apesar de em intervalos temporais não muito similares, a maioria dos dados mostra um período mais úmido que o anterior, porém ainda mais seco que o atual nos últimos $7 \mathrm{ka} \mathrm{AP,} \mathrm{aproximadamente.}$ Segundo Parizzi et al. (1998), a presença de esporos de algas e Lycopodium a partir de 6,1 ka AP testemunha um aumento gradual na umidade em Lagoa Santa. Já entre 5,3 e 4,6 ka AP teria ocorrido um misto de cerrado com florestas galeria e em aproximadamente 4,6 ka AP o clima seria semi-úmido, semelhante ao atual (PARIZZI et al., 1998). Em Lagoa Nova e Lago do Pires ocorrem dois períodos consecutivos de umidificação, quando o cerrado dá lugar ao cerradão e, na seqüencia, este é substituído pela floresta semidecídua nos fundos de vale (BEHLING, 1995, 2003). Ainda nesta região, Enters et al. (2010) aponta para um aumento concomitante de táxons específicos de cerrado e floresta estacional entre 6.900 e $800 \mathrm{ka}$ AP. Esta aparente contradição é explicada pelo aumento da precipitação anual e a existência de estação seca mais curta, com cerca de cinco meses. Em Prados esse período é identificado por uma taxa de deposição mais elevada $\left(0,352 \mathrm{~cm} \mathrm{ano}^{-1}\right)$ (SILVA et al., 2004).
Camadas orgânicas escuras datadas por Araújo et al. (2005) entre $2800 \pm 40$ e $1570 \pm 70$ AP também foram interpretadas como registros de um período de maior umidade.

Segundo Ledru (1993), por volta de 4,5 a $3 \mathrm{ka}$ AP teria ocorrido a dispersão de floresta semi-decídua em Salitre, indicando condições mais úmidas que as atuais. De acordo com Ledru et al. (1998a), o fato de Salitre ser um sítio ainda mais úmido durante este período poderia ser explicado por sua localização num dos caminhos usados pela advecção polar, mantendo um clima úmido e frio ao longo dessa trajetória.

\section{Cenário atual}

Em geral, o clima atual representa o período mais úmido do Holoceno, tendo se estabelecido em diferentes momentos nos sítios analisados. $\mathrm{Na}$ área das lagoas estudadas por Behling (1995; 2003) e Enters et al. (2010) o clima atual teria início apenas entre 970 e 600 anos AP, com a estabilização da floresta semidecídua. No médio Rio Doce o clima atual teria se estabelecido desde cerca de $8 \mathrm{ka} \mathrm{AP}$, com a última transgressão do lago e expansão da floresta semidecídua (RODRIGUES-FILHO et al., 2002). Em Lagoa Santa, apesar do clima atual praticamente ter se estabelecido desde 4,6 ka AP, pequenas oscilações na precipitação entre $3 \mathrm{ka} \mathrm{AP} \mathrm{e} \mathrm{o} \mathrm{presente} \mathrm{foram} \mathrm{ob-}$ servadas (PARIZZI et al., 1998), o que foi confirmado por Salgado-Labouriau et al. (1998) para outras áreas do Brasil Central.

Em Prados, um pequeno período seco teria ocorrido entre 350 e 180 anos AP, o que poderia ser relacionado à Pequena Idade do Gelo européia (séculos XIII a XVIII), quando o clima dos trópicos era mais seco (SILVA et al., 2004). Atualmente esta área apresenta grande diversidade vegetacional, incluindo desde floresta semidecídua e araucárias a cerrados e campos rupestres.

Em geral, os cenários paleobioclimáticos apresentados estão relacionados aos principais eventos climáticos de larga escala descritos na literatura. Os dados da América do Sul tropical acerca do Quaternário Tardio refletem, principalmente, respostas (i) às mudanças ambientais nas áreas fonte de umidade e (ii) às flutuações globais de temperatura (HEINE, 2000). 
Uma maior atenção geralmente é dada pela literatura às condições do UMG. Segundo vários autores, um consenso emerge dos dados paleoambientais de que as temperaturas seriam $5-6^{\circ} \mathrm{C}$ mais baixas que as atuais em $18 \mathrm{ka} \mathrm{AP} \mathrm{(HEINE,} \mathrm{2000;} \mathrm{BUSH} \mathrm{et} \mathrm{al.,}$ 2000, THOMAS, 2000; THOMAS et al., 2001). Em muitos registros este é o período mais frio do último glacial, entretanto, em outros, períodos entre 33 e 30 ka AP e entre 14 e $12 \mathrm{ka} \mathrm{AP}$ parecem ser os mais frios. Essas condições estão de acordo com as expansões de campos apontadas por Behling e Lichte (1997), Ledru (1993) e Oliveira (1992).

No entanto, as estimativas de redução da precipitação durante o UMG são mais díspares e variam de $25-30 \%$ a $50-65 \%$, sendo baseadas em dados proxy, enquanto alguns modelos mostram uma redução em torno de $12 \%$ apenas (THOMAS et al., 2001). Partindo de registros de espeleotemas, Cruz et al. (2009) apontam para períodos mais úmidos durante o último glacial entre 70 e $17 \mathrm{ka}$ AP. Segundo estes autores, o aumento de umidade verificado nesse período estaria relacionado principalmente com: (i) intensificação das monções na América do Sul em fases de elevada insolação, quando o transporte de umidade a partir da bacia amazônica para o sudeste teria sido intensificado em baixos níveis da atmosfera; (ii) a expansão das condições glaciais no hemisfério norte, especialmente o acúmulo de gelo, pois deslocaria um sistema de monções de verão para o sul. Essa proposta está de acordo com modelos gerais de circulação atmosférica para a América do Sul, nos quais o clima do Holoceno é condicionado por mudanças na insolação (VALDES, 2000). Nesse sentido, esses podem ser os mecanismos responsáveis pelos períodos mais úmidos descritos anteriormente nos cenários 2 e 4 . Atualmente, a Zona de Convergência do Atlântico Sul (ZCAS) e a atividade convectiva na bacia amazônica são os principais componentes do Sistema de Monções da América do Sul (JONES ; CARVALHO, 2002).

Por outro lado, assim como verificado em alguns registros de Minas Gerais, segundo Bush et al. (2000), é notável a escassez de registros por volta de $18 \mathrm{ka}$ AP nas terras baixas neotropicais e subtropicais. Ledru (1992) e Ledru et al. (1998b) apontam que o período entre 25 e $16 \mathrm{ka}$ AP foi marcado por uma aridez generalizada no Brasil, responsável por um hiato de cerca de $9 \mathrm{ka}$, período durante o qual houve pedogênese ou uma ausência de deposição de sedimentos orgânicos datáveis em vários registros. A princípio, com o resfriamento do oceano e da superfície continental teria ocorrido uma redução na evapotranspiração e, logo, na formação de nuvens e as fracas circulações trariam menos umidade para o continente, acarretando redução no nível dos lagos e nos totais pluviométricos (BUSH et al., 2000; THOMAS, 2000).

Também como observado nos dados referentes a Minas Gerais, segundo Thomas (2000), o retorno a condições mais úmidas após o UMG ocorreu em diferentes momentos nos trópicos úmidos, podendo ter sido entre 13,5 e $10 \mathrm{ka} \mathrm{AP}$, aproximadamente, ou mesmo no Holoceno Inferior, após o Younger Dryas. Já no Holoceno Inferior e Médio, segundo Dias et al. (2009), os eventos secos verificados (como os cenários 5 e 7) vêm sendo interpretados como causados pela migração da Zona de Convergência Intertropical (ZCI) em direção ao norte, o que estaria ligado a mudanças na insolação explicadas pelos ciclos de Milankovitch.

Vale observar, no entanto, um possível mecanismo de atraso na umidificação do clima no sudeste do Brasil no início do Holoceno, após o período seco entre aproximadamente 11 e $9 \mathrm{ka}$ AP. Sifeddine et al. (2004) analisaram registros de cinco lagos, sendo três localizados na América do Sul (Carajás, Dom Helvécio e Sibéria) e dois na África (Ossa, Barombi-mbo e Bosumtwi). Os resultados mostram que o início do Holoceno foi marcado por condições climáticas mais úmidas e mais quentes, levando ao desenvolvimento florestal nas bacias dos lagos, em conjunto com níveis crescentes dos mesmos, propiciando uma maior produção de fitoplâncton. Apenas o Lago Dom Helvécio, no médio Rio Doce, apresenta um padrão diferenciado, sendo marcado por material $\mathrm{C}_{4}$ terrestre proveniente de uma expansão da savana na bacia do lago. No entanto, como dito anteriormente, a expansão da savana nessa área foi uma resposta à umidificação do clima, cuja continuidade levou ao estabelecimento da floresta estacional semi-decidual na área (RODRIGUES-FILHO et al., 2002). Nesse sentido, o conjunto de informações apresentado por Sifeddine et al. (2004) parece indicar que, pelo menos em relação às bacias dos outros lagos, a umidificação nesta área foi atrasada. Essa tendência de atraso também foi observada por 
Salgado-Labouriau (1997) e aumenta com a latitude, segundo a autora, podendo ser atribuída à forma do continente e à sua posição latitudinal.

A partir de uma análise comparativa entre registros palinológicos de diversos sítios em áreas de cerrado do Brasil, Salgado-Labouriau (1997) apresenta um quadro bastante semelhante ao discutido no presente trabalho: (i) período mais úmido entre $36 \mathrm{e}$ 22-18 ka AP, aproximadamente; (ii) período seco entre 22 e 10,5 ka AP, aproximadamente; e (iii) a partir de 7 ka AP haveria a umidificação do clima, atingindo características semelhantes às atuais por volta de 1,4 ka AP.

\section{CONCLUSÕES E CONSIDERAÇÕES FINAIS}

Dificilmente a correlação dos diferentes eventos climáticos propostos na literatura pode ser feita com limites temporais precisos, em razão das limitações inerentes às metodologias empregadas e às especificidades de cada trabalho. Entretanto, a partir dos resultados e discussões apresentados, conclui-se que: (i) o conjunto de dados disponíveis permite a observação de algumas tendências, principalmente quanto a fases de umidificação e aridificação, o que motivou a proposição de oito cenários paleobioclimáticos para os últimos 50 ka em Minas Gerais; (ii) nos últimos $10 \mathrm{ka}$ se verifica um maior número de cenários, refletindo a maior quantidade e resolução das informações disponíveis; (iii) em geral, os cenários observados estão de acordo com eventos de escala regional propostos na literatura, estando relacionados com mudanças na insolação, nas áreas fonte de umidade e em seus mecanismos de dispersão.

A definição dos cenários paleobioclimáticos em Minas Gerais, no entanto, ainda está em aberto, pois os dados disponíveis estão concentrados em algumas regiões, ocorrendo vazios de informações, principalmente, em áreas do Triângulo, do Norte e do Sul do Estado. Futuras pesquisas com o emprego de novas metodologias tanto para datação (luminescência, isótopos cosmogênicos, etc.) como para a definição de paleoambientes (fitólitos, características geoquímicas e mineralógicas dos depósitos, etc.) podem favorecer uma definição mais precisa dos cenários propostos, bem como vencer os limites metodológicos atuais como, por exemplo, a abrangência temporal da datação radiocarbônica (cerca de $50 \mathrm{ka}$ ).

Apesar de não discutir prováveis condicionantes antrópicos nas alterações bioclimatológicas recentes no Estado, a síntese proposta revela cenários de base para que futuras pesquisas possam discutir tais fenômenos, tendo em vista o elevado grau de devastação, por exemplo, dos biomas Cerrado e Mata Atlântica.

\section{AGRADECIMENTOS}

Os autores agradecem à FAPEMIG pelo auxílio financeiro, bem como a Alex de Carvalho, Letícia Oliveira e Pedro Barros (Laboratório de Geomorfologia IGC/UFMG; Grupo de Pesquisa CNPq Geomorfologia e Recursos Hídricos) pelo auxílio nas pesquisas. Os autores também são gratos ao revisor por suas contribuições.

\section{REFERÊNCIAS}

ABREU, M. L.; ASSIS, W. A ilha de calor em Belo Horizonte: um estudo de caso. In: Congresso Brasileiro de Meteorologia, 10, 1998, Brasília. Anais... Brasília: INMET/SBM, 1998. 5 p.

ALMEIDA, R.M.B. Características climatológicas do regime de chuvas em Minas Gerais. 1995. 64 f. Dissertação (Mestrado) - Universidade Federal de Viçosa, Viçosa, 1995.

ANHUF, D.; LEDRU, M.P.; BEHLING, H.; DA CRUZ JR., F.W.; CORDEIRO, R.C.; VAN DER HAMMEN, T.; KARMANN, I.; MARENGO, J.A.; DE OLIVEIRA; P.E.; PESSENDA, L.; SIFFEDINE, A.; ALBUQUERQUE, A.L.; DA SILVA DIAS, P.L. Paleo-environmental change in Amazonian and African rainforest during the LGM. Palaeogeography, Palaeoclimatology, Palaeoecology, v. 239, p. 510 $-527,2006$. 
ARAUJO, A.G.M.; NEVES, W.A.; PILÓ, L.B.; ATUI, J.P.V. Holocene dryness and human occupation in Brazil during the "Archaic Gap". Quaternary Research, v. 64, p. $298-307,2005$.

BEHLING, H. A high resolution Holocene pollen record from Lago do Pires, SE Brazil: Vegetation, climate and fire history. Journal of Paleolimnology, v. 14, p. $253-268,1995$.

South and southeast Brazilian grasslands during Late Quaternary times: a synthesis. Palaeogeography, Palaeoclimatology, Palaeoecology, v. 177, p. $19-27,2002$.

. Late glacial and Holocene vegetation, climate and fire history inferred from Lagoa Nova in the southeastern Brazilian lowland. Veget Hist Archaeobot, v. 12, p. $263-270,2003$.

BEHLING, H.; LICHTE, M. Evidence of dry and cold climatic conditions at glacial times in tropical southeastern Brazil. Quaternary Research, v. 48, p. $348-358,1997$.

BEHLING, H.; et al. Late Quaternary vegetational and climate dynamics in southeastern Brazil, inferences from marine cores GeoB 3229-2 and GeoB 3202-1. Palaeogeography, Palaeoclimatology, Palaeoecology, v. 179, p. $227-243,2002$.

BENITES, V.M.; CAIAFA, A.N.; MENDONÇA, E.S.; SCHAEFER, C.E; KER, J.C. Solos e vegetação nos complexos rupestres de altitude da Mantiqueira e do Espinhaço. Floresta e Ambiente, v. 10, p. 76 - 85, 2003.

BORBA-ROSCHEL, M.; ALEXANDRE, A.; VARAJÃO, A. F. D. C.; MEUNIER, J. D.; VARAJÃO, C. A. C.; COLIN, F. Phytoliths as indicators of pedogenesis and paleoenvironmental changes in the Brazilian cerrado. Journal of Geochemical Exploration, n. 88, p. $172-176,2006$.

BRASIL. Departamento Nacional de Meteorologia. Ministério da Agricultura e Reforma Agrária. Normais Climatológicas. Brasília, 1992. 84 p.

BUSH, M.B.; STUTE, M.; LEDRU, M.-P.; BEHLING, H.; COLINVAUX, P.A.; DE OLIVEIRA, P.E.; GRIMM, E.C.; HOOGHIEMSTRA, H.; HABERLE, S.; EYDEN, B.W.; SALGADO-LABOURIAU, M.L.; WEBB, R. Paleotemperature estimates for the lowland Americas between $30^{\circ} \mathrm{S}$ and $30^{\circ} \mathrm{N}$ at the last glacial maximum. In: MARKGRAF, V. (Ed.). Interhemispheric Climate Linkages: Present and Past Interhemispheric Climate Linkages in the Americas and their Societal Effects. New York: Academic Press, 2001. p. $293-306$.

CARNEIRO FILHO, A. Cerrados amazônicos: fósseis vivos? Algumas reflexões. Revista. $I G$, v. 14, p. $63-68,1993$.

CARTelle, C. Tempo Passado: Mamíferos do Pleistoceno em Minas Gerais. Belo Horizonte: Palco, 1994. $131 \mathrm{p}$.

CRUZ, F.W.; WANG, X.; AULER, A.; VUILLE, M.; BURNS, S.J.; EDWARDS, L.R.; KARMANN, I.; CHENG, H. Orbital and millennial-scale precipitation changes in Brazil from speleothem records. In: VIMEUX, F.; SYLVESTRE, F.; KHODRI, M. (Ed.). Past Climate Variability in South America and Surrounding Regions: From the Last Glacial Maximum to the Holocene. Springer, 2009. v. 14, cap. 2, p. 29-60.

DESJARDINS, T.; CARNEIRO FILHO, A.; MARIOTTI, A.; CHAUVEL, A.; GIRARDIN, C. Changes of forest-savanna boundary in Brasilian Amazonia dur-

Soc. \& Nat., Uberlândia, ano 23 n. 3, 371-386, set/dez. 2011 
ing holocene revealed by stable isotope ratios of soil organic carbon. Oecologia, v. 108, p. 749-756, 1996.

DIAS, P.L.S.; TURCQ, B.; DIAS, M.A.F.S.; BRACONNOT, P.; JORGETTI, T. Mid-Holocene climate of tropical South America: a model-data approach. In: VIMEUX, F.; SYLVESTRE, F.; KHODRI, M. (Ed.). Past Climate Variability in South America and Surrounding Regions: From the Last Glacial Maximum to the Holocene. Springer, 2009. v. 14, cap. 11, p. $259-282$.

ENTERS, D.; BEHLING, H.; MAYR, C.; DUPONT, L.; ZOLITSCHKA, B. Holocene environmental dynamics of south-eastern Brazil recorded in laminated sediments of Lago Aleixo. J Paleolimnol, 44, p. 265 $-277,2010$.

FERREIRA, A. B. Variabilidade climática e dinâmica geomorfológica. Publicações da Associação Portuguesa de Geomorfólogos, v. 1, p. 7 - 15, 2002.

FERRI, M. G. Vegetação Brasileira. 1ed. São Paulo: USP, 1980. 157p.

GOMES, M. O. S.; RODRIGUES, M. F.; DELICIO, M. P. Evolução paleoclimática e paleoecológica da bacia do Rio Maracujá, Ouro Preto (MG), com base na microflora. In: CONGRESSO BRASILEIRO DE PALEONTOLOGIA, 21, 2009, Belém. Anais... Belém, 2009, p. 37.

HEINE, K. Tropical South America during the Last Glacial Maximum: evidence from glacial, periglacial and fluvial records. Quaternary International, 72, p. $7-21,2000$.

HOUGHTON, J. T., DING, Y., GRIGGS, D. J., NOGUER, M., VAN DER LINDEN, P., DAI, X.,
MASKELL, K., JOHNSON, C. I. Climate change 2001: the scientific basis. Contribution of Working Group I to the Third Assessment Report of the Intergovernmental Panel on Climate Change. Cambridge University Press, Cambridge, 2001, 944 p.

IBGE. Mapa de biomas do Brasil: escala 1:5.000.000. Rio de Janeiro: IBGE, 2004a.

IBGE. Mapa de Vegetação do Brasil: escala 1:5.000.000. Rio de Janeiro: IBGE, 2004b.

JACOB, J.; HUANG, Y.; DISNAR, J.-R.; SIFEDDINE, A.; BOUSSAFIR, M.; ALBUQUERQUE, A.L.S.; TURCQ, B. Paleohydrological changes during the last deglaciation in Northern Brazil. Quaternary Science Reviews, v. 26, p. 1004 - 1015, 2007.

JONES, C.; CARVALHO, L.M.V. Active and break phases in the South America monsoon system. Journal of Climate, v. 15, p. 905 - 914, 2002.

KRAMER, V. M. S.; STEVAUX, J. C. Mudanças climáticas na região de Taquaruçu (MS) durante o holoceno. Boletim Paranaense de Geociências, n. 49, p. $79-91,2001$.

LEDRU, M.-P. Modification de la végétation du Brásil central entre la dernière époque glaciaire et l'interglaciaire actuel. Comptes Rendus de l'Academie des Sciences, II, 314, p. 117 - 123, 1992.

LEDRU, M.-P. Late Quaternary environmental and climatic changes in central Brazil. Quaternary Research, v. 39, p. $90-98,1993$.

LEDRU, M.-P., SOARES BRAGA, P. I., SOUBIE'S, F., FOURNIER, M., MARTIN, L., SUGUIO, K., AND TURCQ, B. The last 50,000 years in the Neotropics 
(Southern Brazil): evolution of vegetation and climate. Palaeogeography Palaeoclimatology, Palaeoecology, v. 123, p. $239-257,1996$.

LEDRU, M.-P., SALGADO LABOURIAU, M.L., LORSCHEITTER, M.L. Vegetation dynamics in Brazil during the last 10,000 yr B. P. Review of Palaeobotany and Palynology, v. 99, p. 131 - 142, 1998a.

LEDRU, M.-P., BERTAUX, J., SIFEDDINE, A., SUGUIO, K. Absence of last glacial maximum records in lowland tropical forest. Quaternary Research, v. 49 , p. $233-237,1998$ b.

LEDRU, M.-P.; Mourguiart, P.; Riccomini, C. Related changes in biodiversity, insolation and climate in the Atlantic rainforest since the last interglacial. Palaeogeography, Palaeoclimatology, Palaeoecology, v. 271, p. $140-152,2009$.

LINO, G. L. Alguns fatos básicos sobre mudanças climáticas. OIKOS, v. 9, n. 1, p. 177 - 188, 2010.

MEIS, M. R. M. Indícios de variações climáticas neo-quaternárias no médio vale do Rio Doce. Anuário do Instituto de Geociências (UFRJ), v. 1, p. 110 - 113, 1977.

MIALL, A. The geology of fluvial deposits: sedimentary facies, basin analysis, and petroleum geology. 4. ed. New York: Springer, 2006, 582 p.

MISSURA, R.; CORRÊA, A. C. B. Evidências geomorfológicas como ferramentas para a reconstrução paleogeográfica na Mantiqueira Ocidental-MG. Revista de Geografia (Recife), v. 24, p. 268 -287, 2007.

NIMER, E. Climatologia do Brasil. 2ed. Rio de Janeiro: Fundação IBGE, 1989. 421 p.
NOBRE, C.A.; SAMPAIO, G.; SALAZAR, L. Mudanças climáticas e Amazônia. Mudanças climáticas/ artigos. Ciência e Cultura, v. 59, n. 3, Jul./Set. 2007.

OLIVEIRA, P.E. A palynological Record of late Quaternary vegetational and climatic change in southeastern Brazil. Tese. Columbus, The Ohio State University - USA, 1992. 238 p.

PARIZZI, M. G.; SALGADO-LABOURIAU, M. L.; KHOLER, H. C. Genesis and environmental history of Lagoa Santa, southeastern Brazil. The Holocene, v. 8 , p. $311-321,1998$.

PESSENDA, L.C.R., ARAVENA, R., MELFI, A.J., BOULET, $R$. The use of carbon isotopes (C-13, C-14) in soil to evaluate vegetation changes during the Holocene in central Brazil. Radiocarbon, v. 38, n. 2, p. $191-201,1996$.

PESSENDA, L. C. R.; RIBEIRO, A. S.; GOUVEIA, S. E. M.; ARAVENA, R.; BOULET, R.; BENDASSOLLI, J. A. Vegetation dynamics during the late Pleistocene in the Barreirinhas region, Maranhão State, northeastern Brazil, based on carbon isotopes in soil organic matter. Quaternary Research, v. 62, p. $183-193,2004$.

RATTER, J.A.; RIBEIRO, J. F.; BRIDGEWATER, S. The Brazilian cerrado vegetation and threats to its biodiversity. Annals of Botany, n. 80, p. 223 -230, 1997

RIZZINI, C.T. Tratado de Fitogeografia do Brasil - Aspectos sociológicos e florísticos. São Paulo: HUCITEC / EDUSP, 1979. 374 p.

RODRIGUES FILHO, S.; BEHLING, H.; IRION, G.; MÜLLER, G. Evidence for lake formation as a response to an inferred Holocene climatic transition in Brazil. Quaternary Research, v. 57, p. 131 - 137, 2002. 
SALGADO LABOURIAU, M. L. Late Quaternary palaeoclimate in the savannas of South America. Journal of Quaternary Science, v. 12, n. 5, p. 371 - 379, 1997.

SALGADO LABOURIAU, M. L.; BARBERI, M.; FERRAZ VICENTINI, K. R.; PARIZZI, M.G. A dry climatic event during the late Quaternary of tropical Brazil. Review of Palaeobotany and Palynology, v. 99, p. 115 - 129, 1998.

SALLUN, A. E. M.; SUGUIO, K.; TATUMI, S. H.; YEE, M.; SANTOS, J.; BARRETO, A. M. F. Datação absoluta de depósitos quaternários brasileiros por luminescência. Revista Brasileira de Geociências, v. 37, n. 2, p. $401-412,2007$.

SCHUMM, S. A. River Variability and Complexity. New York: Cambridge University Press, 2005. 220 p.

SIFEDDINE, A.; WIRRMANNC, D.; ALBUQUERQUE, A. L. S.; TURCQ, B.; CORDEIRO, R.C.; GURGELA, M.H.C.; ABRÃO, J. J. Bulk composition of sedimentary organic matter used in palaeoenvironmental reconstructions: examples from the tropical belt of South America and Africa. Palaeogeography, Palaeoclimatology, Palaeoecology, 214, p. 41- 53, 2004.

SILVA, A. C.; VIDAL-TORRADO, P.; MARTINEZ CORTIZAS, A.; GARCIA RODEJA, E. Solos do topo da Serra São José (Minas Gerais) e suas relações com o paleoclima no sudeste do Brasil. Revista Brasileira de Ciências do Solo, v. 28, p. 455-466, 2004.

SOS MATA ATlÂNTICA. Mata Atlântica. Disponível em: http://www.sosmatatlantica.org.br/index. php?section=info\&action=mata. Acesso em: 15 abr 2011.

THOMAS, M. F. Late Quaternary environmental changes and the alluvial record in humid tropical environments. Quaternary International, v. 72, p. $23-36,2000$.

THOMAS, M. F.; NOTT, J.; PRICE, D. M. Late Quaternary stream sedimentation in the humid tropics: a review with new data from NE Queensland, Australia. Geomorphology, v. 39, p. $53-68,2001$.

TURCQ, B.; ALBUQUERQUE, A. L. S.; CORDEIRO, R. C.; SIFEDDINE, A.; SIMOES FILHO, F. F. L.; SOUZA, A. G.; ABRÃO, J. J.; OLIVEIRA, F. B. L.; SILVA, A. O.; CAPITÂNEO, J. Accumulation of organic carbon in five Brazilian lakes during the Holocene. Sedimentary Geology, v. 148, p. 319 $-342,2002$.

URREGO, D. H.; SILMAN, M. R.; BUSH, M. B. The Last Glacial Maximum: stability and change in a western Amazonian cloud Forest. Journal of Quaternary Science, v. 20, n. 7-8, p. $693-701,2005$.

VALDES, P.J. South American palaeoclimate model simulations: how reliable are the models? Journal of Quaternary Science, v. 15, n. 4, p. $357-368,2000$.

VIANELLO, R.L. Indícios de Mudanças Climáticas Causadas por Desmatamento: Município de Juiz de Fora - MG. Boletim Geográfico (Rio de Janeiro), v. 34, n. 251, p. 139 - 150, 1976. 